\title{
Translating intentions into nutrition behaviors via planning requires self-efficacy: Evidence from Thailand and Germany
}

\author{
Ralf Schwarzer, Jana Richert, Pimchanok Kreausukon, Lena Remme, \\ Amelie U. Wiedemann, and Tabea Reuter
}

Freie Universität Berlin, Berlin, Germany

\begin{abstract}
$A$ first step towards the improvement of daily dietary behaviors is forming an intention to change one's nutrition. However, an intention by itself is not sufficient for successful action. Rather, to translate intentions into behavior, careful planning is recommended. Thus, planning constitutes a mediator between the intention and the behavior. However, if a person lacks self-efficacy, this mediation might fail. Previous research in Costa Rica and South Korea has identified perceived self-efficacy as a moderator of the intention-planningbehavior relationship. To examine further the moderator role of self-efficacy, two additional studies were designed in Thailand and Germany. Study 1 surveyed 1718 Thai university students in terms of a low-fat diet; Study 2 surveyed 1140 German internet users in terms of their fruit and vegetable consumption at two measurement points in time, 6 months apart. Intentions served as predictor, planning as mediator, self-efficacy as moderator, and behaviors as outcomes. First, intentions were translated into nutrition behaviors by planning. Second, self-efficacy moderated this mediation in both studies: The strength of the mediated effect increased along with levels of self-efficacy, even when accounting for baseline behaviors. For planning to mediate the intention-behavior relation, people must not harbor self-doubts. If they lack self-efficacy, intentions are not well translated into nutrition behavior through planning.
\end{abstract}

Keywords: Self-efficacy; Intentions; Planning; Nutrition; Moderated mediation.

$T$ ne première étape vers l'amélioration des comportements diététiques quotidiens est d'avoir l'intention de changer sa nutrition. Cependant, une intention n'est pas suffisante à elle seule pour garantit la réussite de l'action. Afin de transformer l'intention en comportement, une planification minutieuse est recommandée. Ainsi, la planification constitue un facteur médiateur entre l'intention et le comportement. Cependant, si une personne manque d'auto-efficacité, cette médiation risque l'auto-efficacité perçue joue un rôle modérateur dans la relation intention-planification-comportement. Dans le but d'examiner plus à fond ce rôle modérateur de l'auto-efficacité, deux études additionnelles furent réalisées en Thaïlande et en Allemagne. L'étude 1 fut menée auprès de 1718 étudiants universitaires thailandais aux termes d'une diète pauvre en matières grasses, tandis que l'étude 2 fut réalisée auprès 1140 utilisateurs d'internet allemands aux termes d'une consommation composée de fruits et de légumes, à deux temps de mesure séparés par un intervalle de 6 mois. Les intentions constituaient la variable indépendante, la planification la variable médiatrice, l'auto-efficacité la variable modératrice et les comportements la variable dépendante. Premièrement, les résultats ont indiqué que les intentions ont été traduites en comportements de nutrition par le biais de la planification. Deuxièmement, l'auto-efficacité a modéré cette relation dans les deux études: la force de l'effet médiateur a augmenté en fonction des niveaux d'auto-efficacité, même en tenant compte des comportements de base. Afin que la planification puisse jouer un rôle médiateur sur la relation intention-comportement, les gens ne doivent pas entretenir des doutes à l'égard d'eux-mêmes. S'ils manquent d'auto-efficacité, les intentions ne sont pas bien traduites en comportements de nutrition par le biais de la planification.

$F^{1}$ primer paso para la mejora de la conducta de dieta diaria consiste en formar la intención de cambiar la $\mathcal{E}$ nutrición de uno. Sin embargo, la intención en sí no es suficiente para la acción exitosa. Más bien, se

Correspondence should be addressed to Ralf Schwarzer, Health Psychology, Freie Universität Berlin, Habelschwerdter Allee 45, 14195 Berlin, Germany. (E-mail: health@zedat.fu-berlin.de). 
recomienda una cuidadosa planificación para trasladar las intenciones a la conducta. Por tanto, la planificación constituye un mediador entre la intención y la conducta. Sin embargo, si la persona no tiene auto-eficacia, esta mediación puede fallar. La investigación previa en Costa Rica y en Corea del Sur identificó la auto-eficacia percibida como moderador de la relación intención-planificación-conducta. Para seguir investigando el rol moderador de la auto-eficacia, dos estudios adicionales fueron diseñados en Tailandia y en Alemania. El Estudio 1 encuestó a 1718 estudiantes universitarios tailandeses en términos de la dieta baja en grasa, mientras que el Estudio 2 encuestó a 1140 usuarios de internet alemanes en términos de consumo de frutas y verduras en dos puntos de medición separados en seis meses. Las intenciones sirvieron como predictor, la planificación como mediador, la auto-eficacia como moderador y las conductas como resultados. Primero, se trasladaron las intenciones en conductas de nutrición y planificación. Segundo, la auto-eficacia moderó esta mediación en ambos estudios: La fuerza del efecto mediador se incrementó junto con los niveles de auto-eficacia, incluso cuando se contabilizaron las conductas de la línea base. Para que la planificación medie la relación intención-conducta, las personas no pueden tener auto-dudas. Si no tienen auto-eficacia, las intenciones no se trasladan bien a la conducta de nutrición mediante la planificación.

Eating a low-fat diet and consuming a sufficient amount of fruit and vegetables are regarded as main components of a healthy diet that might prevent cardiovascular diseases and other ailments (WHO, 2003). But poor dietary habits are difficult to change, and various psychosocial factors are associated with such changes (Shaikh, Yaroch, Nebeling, Yeh, \& Resnicow, 2008; Steptoe et al., 2003). To adhere to the recommendations, one has to form an explicit behavioral intention. However, intentions often fail to be translated into corresponding behaviors. Thus, additional psychological constructs must be studied to elucidate the mechanisms that are involved in health behavior change.

\section{INTENTIONS, PLANNING, AND BEHAVIOR}

Although the construct of intention is indispensable in explaining health behavior change, its predictive value is limited. When trying to translate intentions into behavior, individuals are faced with various obstacles, such as distractions, forgetfulness, temptations, or conflicting bad habits. Godin and Kok (1996), who reviewed 19 studies, found a mean correlation of .46 between intention and health behavior, such as exercise, screening attendance, and addictions. Abraham and Sheeran (2000) reported behavioral intention measures to account for $20-25 \%$ of the variance in health-behavior measures. People often do not behave according to their intentions (Scholz, Nagy, Göhner, Luszczynska, \& Kliegel, 2009; Sniehotta, 2009). Therefore, intentions need to be supplemented by other, more proximal factors that might facilitate the translation of intentions into action (Wiedemann, Schüz, Sniehotta, Scholz, \& Schwarzer, 2009). Some facilitators have been identified, such as perceived self-efficacy and planning. However, it is not fully understood how these two factors interplay with intentions and behaviors. Previous studies have specified selfefficacy and planning as mediators between intentions and behaviors (e.g., Schwarzer, Luszczynska, Ziegelmann, Scholz, \& Lippke, 2008). Recently, the question has been raised whether self-efficacy might rather operate as a moderator (GutiérrezDoña, Lippke, Renner, Kwon, \& Schwarzer, 2009; Lippke, Wiedemann, Ziegelmann, Reuter, \& Schwarzer, 2009). One purpose of the present study is to test whether planning mediates the intention-behavior relationship. Primarily, however, an interaction between intentions and selfefficacy and its effect on the assumed mediation is examined. This is done in order to elucidate the mechanisms that come into play after people have formed an intention to change their dietary behaviors.

\section{The mediator role of planning}

Good intentions are more likely to be translated into action when people plan when, where, and how to perform the desired behavior. Intentions foster planning, which in turn facilitates behavior change. Planning has been found to mediate the intention-behavior relation (Gollwitzer \& Sheeran, 2006). Why does planning facilitate the impact of good intentions on behavior? Planning is more than simply an extension of an intention because it includes specific situation parameters ("when," "where") and a sequence of action ("how"). It is more effective than intentions when it comes to the likelihood and speed of performance, partly because behavior might be elicited almost "automatically" when the relevant situational cues are encountered. People tend to remember better their intentions when specified in a when, where, and how manner (for an overview 
and meta-analysis, see Gollwitzer \& Sheeran, 2006). This has important implications for health-behavior interventions. Planning is an alterable variable. It can be easily communicated to individuals with self-regulatory deficits. Several randomized controlled trials have documented the evidence in favor of such planning interventions (e.g., Chapman, Armitage, \& Norman, 2009; Luszczynska, Sobczyk, \& Abraham, 2007).

Although planning generally has been found to mediate the intention-behavior relation, some studies have failed to find such effects (Norman $\&$ Conner, 2005). This suggests that the relationships between intentions, planning, and behavior might also depend on other factors. For example, the degree to which planning mediates between intention and behavior has been found to be higher in older than in younger individuals (Renner, Spivak, Kwon, \& Schwarzer, 2007; Scholz, Sniehotta, Burkert, \& Schwarzer, 2007).

\section{Self-efficacy as a putative moderator}

Perceived self-efficacy is one potential moderator for the degree to which planning mediates the intention-behavior relationship. This construct reflects optimistic self-beliefs when overcoming temptations or adopting a novel course of action. Different challenges have to be met during the course of dietary behavior change. Self-efficacy beliefs are required to master these tasks successfully. Perceived self-efficacy has been found to be important at all points in the health behavior change process including dietary changes (Bandura, 1997; Linde, Rothman, Baldwin, \& Jeffery, 2006). It is expected to moderate the intention-planning-behavior relation because people harboring self-doubts might either fail to translate intentions into plans or fail to act upon their plans. For persons with a high level of selfefficacy, planning might be more likely to facilitate goal achievement because optimistic self-beliefs instigate planning. Also, self-efficacious people feel more confident about translating their plans into actual behavior. In other words, whether intentions affect behavior via planning (mediation) might depend on the individual's level of selfefficacy (moderator).

\section{Rationale for moderated mediation analysis}

Mediation describes how an effect occurs, that is, how an independent variable $(X)$ affects a dependent variable $(Y)$ via a mediator $\left(M_{\mathrm{e}}\right)$. By this, the total effect of $X$ on $Y$ is decomposed into the direct effect $(X \rightarrow Y)$ and the indirect effect $(X \rightarrow$ $\left.M_{\mathrm{e}} \rightarrow Y\right)$. Complete mediation is the case in which $X$ no longer affects $Y$ after $M_{\mathrm{e}}$ has been controlled for, whereas in partial mediation, the path coefficient from $X$ to $Y$ is lowered in size but remains significantly different from zero when the mediator is controlled for (Aiken \& West, 1991; Kenny, 2008; MacKinnon, 2008). A mediator might emerge in one group (e.g., high selfefficacious persons), but not in another (e.g., low self-efficacious persons). In such a case, selfefficacy operates as a moderator of the mediating relationship. There are several ways of a moderated mediation. For example, the effect of $X$ on the mediator may differ as a function of the moderator $\left(M_{\mathrm{o}}\right)$, or the mediator may interact with the moderator to affect $Y$. In the first case, there is an interaction between $X$ and $M_{\mathrm{o}}$. In the second case, there is an interaction between $M_{\mathrm{e}}$ and $M_{\mathrm{o}}$ (Preacher, Rucker, \& Hayes, 2007). Both kinds of moderated mediation may be of equal value to elucidate the mechanisms of behavior change.

\section{Previous evidence from Costa Rica and South Korea}

Two earlier studies have been designed to examine the moderating role of self-efficacy in the intention-planning-dietary behavior relationship (Gutiérrez-Doña et al., 2009). A cross-sectional study in Costa Rica included 245 women with a mean age of 40 years who were involved in a workplace health promotion program for lifestyle changes, including adherence to a low-fat diet. A longitudinal study in South Korea included 358 women with a mean age of 36 years who were also surveyed in terms of a low-fat diet. Moderated mediation models were specified in which planning served as a mediator between intentions and dietary behavior. Self-efficacy was specified as a moderator of the intention-planning-behavior relationship. It turned out that intentions were translated into dietary behavior by planning. Moreover, levels of self-efficacy moderated this mediation process: The strength of the mediated effect increased along with levels of self-efficacy, even when accounting for baseline dietary behaviors. It has been concluded by the authors that, for planning to mediate the intention-behavior relation, people must harbor sufficient levels of self-efficacy. If they lack self-efficacy, either intentions are not well translated into planning or planning is not well translated into dietary behavior. These first results shed light on some of 
the mechanisms of health behavior change that need to be replicated using different samples and contexts to arrive at valid conclusions.

\section{Aims of the two studies in Thailand and Germany}

Our general assumption is that people need a certain level of perceived self-efficacy for most processes of health-behavior change. Therefore, we search for empirical evidence across various samples, contexts, and health behaviors. Our current two studies analyze whether planning (mediator variable) mediates the effect of intentions (independent variable) on dietary behavior (dependent variable) as a function of self-efficacy levels (moderator).

\section{STUDY 1: SURVEY ADDRESSING A LOW-FAT DIET IN THAI UNIVERSITY STUDENTS}

The study in Thailand was conducted in collaboration with the Freie Universität Berlin to contribute to the cross-cultural validation of research on health-behavior change. In particular, this study was inspired by previous research in Costa Rica and South Korea, with the aim of replicating its findings (Gutiérrez-Doña et al., 2009).

\section{Method}

\section{Participants}

Students at four universities in Thailand took part in a survey on healthy nutrition: Chiang Mai (Chiang Mai University), Khonkaen (Khonkaen University), Bangkok (Kasetsart University), and Songkla (Prince of Songkla University). A total of 1718 students responded, of whom 917 were women $(53.4 \%)$. They studied in the first
$(28.6 \%)$, second $(32.8 \%)$, third $(19.3 \%)$, and fourth $(19.2 \%)$ academic years in the areas of humanities and social sciences $(53.6 \%)$, science and technology (31.4\%), and health sciences $(15 \%)$. Their mean age was 20 years $(S D=1.4)$, with a range from 17 to 30 years. Their body mass index (BMI) averaged $20.6(S D=3.1)$, with a range from 11 to 40 .

\section{Procedure}

Participants were recruited at the universities. After giving informed consent, participants were asked to complete a questionnaire assessing socialcognitive variables (e.g., self-efficacy, intentions, planning) as well as dietary behaviors. The questionnaire took approximately $10 \mathrm{~min}$ to complete.

\section{Measures}

Means, standard deviations, and intercorrelations are displayed in Table 1. Item examples given below are translations from Thai. German versions of all scales were tested in several prior studies with respect to psychometric properties (see Schwarzer, 2008).

Intentions were measured by the item "I intend to eat less fat," followed by a six-point scale ranging from not at all true (1) to definitely true (6).

Planning was assessed by the item "I have planned exactly when and how I will change my dietary behaviors," followed by a six-point scale ranging from not at all true (1) to definitely true (6).

Perceived self-efficacy was assessed by the tenitem General Self-Efficacy Scale (Schwarzer \& Jerusalem, 1995). Item examples are "I can solve most problems if I invest the necessary effort," and "It is easy for me to stick to my aims and accomplish my goals," followed by a six-point

TABLE 1

Means $(M)$, standard deviations $(S D)$, and intercorrelations for intention, planning, self-efficacy, and low-fat dietary behaviors in 1718 Thai participants

\begin{tabular}{lccccccc}
\hline & Age & Sex & BMI & Intention & Planning & Self-efficacy & Low-fat diet \\
\hline Range & & & & $1-6$ & $1-6$ & $1-6$ & $6-36$ \\
$M$ & 20.19 & 1.53 & 20.58 & 3.65 & 3.43 & 3.87 & 21.48 \\
$S D$ & 1.44 & .50 & 3.08 & 1.33 & 1.26 & 0.69 & 5.29 \\
Intention & .00 & $.14^{* *}$ & $.05^{*}$ & 1.00 & & & \\
Planning & $-.05^{*}$ & $.12^{* *}$ & .02 & $.38^{* *}$ & 1.00 & & \\
Self-efficacy & $.06^{*}$ & -.02 & .02 & $.24^{* *}$ & $.28^{* *}$ & 1.00 & $.32^{* *}$ \\
Low-fat diet & -.01 & $.15^{* *}$ & -.04 & $.65^{* *}$ & $.48^{* *}$ & .00 \\
\hline
\end{tabular}

$\mathrm{BMI}=$ body mass index; sex: $1=$ male, $2=$ female. ${ }^{*} p<.05 ;{ }^{* *} p<.01$. 
scale ranging from not at all true (1) to definitely true (6) (Cronbach's alpha =.93).

Dietary behavior was assessed by a six-item scale that targeted a low-fat diet, such as "When I drink milk or eat milk products, I choose low-fat products (e.g., low-fat milk)," I always remove the visible fat from my food (e.g., from steaks or belly of pork), and "I avoid cholesterol-rich food." Responses were made on six-point scales ranging from not at all true (1) to definitely true (6) (Cronbach's alpha $=.79$ ).

\section{Analytical procedure}

The analyses were based on procedures recommended by Preacher et al. (2007) that represent various multiple regression models. Two moderated mediator models were tested, where selfefficacy was chosen as a moderator of the intention-planning-behavior relationship. Therefore, interactions either between self-efficacy and intentions ("Model 2") or between selfefficacy and planning ("Model 3") were tested using the MODMED macro (Version 1.1) by Preacher et al. (2007). For the predictors, including the interaction term, standardized variables were used (Aiken \& West, 1991). Missing data $(<2 \%)$ were imputed using the Expectation Maximization (EM) algorithm in SPSS 15 (Enders, 2001).

\section{Results}

\section{Self-efficacy moderates the planning-behavior relationship}

Model 3 did not yield a significant moderation effect, which means that the Self-Efficacy $x$ Planning interaction did not become significant. Subsequently, Model 2 was tested. First, planning was predicted by intentions $(B=0.31, p<.01)$, self-efficacy $(\mathrm{B}=0.19, p<.01)$, and the interaction between intention and self-efficacy $(B=0.10$, $p<.01$ ), accounting jointly for $18 \%$ of the planning variance. The significant interaction effect is a necessary condition for moderated mediation (Figure 1). Dietary behavior was predicted by intentions $(B=0.54, p<.01)$ and planning $(B=0.28, p<.01)$, which accounted for $48 \%$ of the variance in dietary behaviors. Planning partially mediated the intention-behavior relation, and this mediation was moderated by perceived self-efficacy. That is, the higher the self-efficacy scores, the higher the indirect effect of intentions on behavior through planning.

Analyses were run on the null hypothesis that the conditional indirect effect does not differ significantly from zero at specific values of the moderator. Planning mediated the effect of intentions on dietary behavior only if the individual self-efficacy score was higher than 2.37 on the 1-6 scale. When splitting the sample at this point, the mediation for the high self-efficacy group was significant (Sobel $z=10.85, p<.0001$ ), whereas the mediation for the low self-efficacy group was not (Sobel $z=1.49, p=.136$ ). Thus, only participants with a score of at least 2.37 belonged to the high self-efficacy subgroup in which intentions were translated by planning into behavior.

\section{Discussion of Study 1}

The moderated mediation effects in the Thai sample replicate earlier findings in Costa Rican women (Gutiérrez-Doña et al., 2009; Study 1; cross-sectional) as well as in South Korean women (Gutiérrez-Doña et al., 2009; Study 2; longitudinal), although the parameters differed as well as the type of interaction. In the Costa Rican study self-efficacy and planning interacted, whereas in the South Korean study intention and self-efficacy interacted in the same way as in the Thai sample. The Thai study focused on a low-fat diet with a very similar operationalization as in the two previous studies. The moderation type (Intention $\times$ Planning) is the same as in South Korea, but different from the one in Costa Rica (Planning $\times$ Nutrition). Further studies are necessary to determine why different patterns emerged.

Moreover, in the two previous studies in Costa Rica and Korea, self-efficacy had been operationalized in a narrow, behavior-specific manner (nutrition self-efficacy), whereas in the Thai study general self-efficacy had been measured, not addressing dietary behaviors. The fact that the moderated mediation effect was replicated in spite of this scale incongruence may suggest an overall effect of optimistic self-beliefs on goal pursuit. Further research needs to address this hypothesis

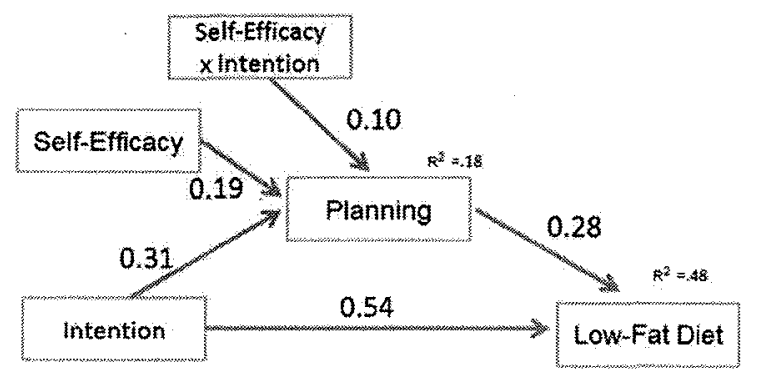

Figure 1. Moderated mediation model for 1718 Thai university students (Study 1). All coefficients $p<.01$. 
by varying the levels of self-efficacy specificity for various behaviors.

\section{STUDY 2: LONGITUDINAL RESEARCH ON FRUIT AND VEGETABLE CONSUMPTION IN GERMAN ADULTS}

The previous analyses have confirmed the mediation of the intention-behavior relationship by planning, and the moderation of this mediation by levels of perceived self-efficacy. This had been done only cross-sectionally and, thus, did not target behavior change. To account for baseline behavior, the analyses need to be replicated including Time 1 dietary behavior as a covariate. A longitudinal study of 1140 German internet users provided such data. Apart from the inclusion of the baseline covariate, the analytical procedure was the same as in Study 1.

\section{Method}

\section{Participants and procedure}

An online study on dietary behaviors and physical activity was launched to survey these behaviors in Germany. It was advertised by press releases (magazine reports, university press), announcements on university websites, and mailing lists. Follow-up measures at Time 2 (T2) were taken four weeks after baseline assessments (Time $1 ; \mathrm{T} 1)$. The section on fruit and vegetable intake is the subject of the present analysis. The initial sample $(N=2945)$ comprised persons with valid e-mail addresses who completed the $\mathrm{T} 1$ fruit and vegetable assessment. Those who also answered the follow-up questionnaire constituted the longitudinal sample ( $n=1140 ; 39 \%$ of baseline). This sample comprised $19 \%$ men and had a mean age of 37.3 years, $S D=12.5$, ranging from 16 to 77 years.

\section{Attrition analysis}

The original sample at Time 1 did not differ from the longitudinal sample in terms of age $(t=0.40, \quad p>.05)$ and intentions $(t=0.29$, $p>.05)$. However, there was a selective dropout in terms of sex $(t=2.34, p<.01)$ and portions of fruit and vegetable intake $(t=3.79, p<.01)$. More women than men returned the questionnaire at Wave 2, and average baseline number of portions was 3.10 for returners, but only 2.93 for dropouts.

\section{Measures}

Means, standard deviations, and intercorrelations are displayed in Table 2. All scales were tested in several prior studies with respect to psychometric properties (see Schwarzer, 2008). Responses were made on four-point scales ranging from not at all true (1) to exactly true (4).

Intentions at $\mathrm{Tl}$ were measured with two items, namely (a) "I intend to eat at least five servings of fruit or vegetable per day," and (b) "I intend to eat fruit or vegetables with meals or between meals" $(r=.54)$.

Planning at T2 was measured with two items, such as, "I have already precisely planned when, where, and how to eat five servings of fruit or vegetables throughout the day" $(r=.78)$.

\section{Perceived self-efficacy}

The self-efficacy scale at $\mathrm{T} 2$ comprised three items, such as "I am confident that I can eat five servings of fruit and vegetables a day" (Cronbach's $\alpha=.87$ ).

TABLE 2

Means $(M)$, standard deviations $(S D)$, and intercorrelations for intention, planning, self-efficacy, and dietary behaviors (portions of fruit and vegetables per day) in 1140 German adults

\begin{tabular}{lccccccc}
\hline & Age & Sex & Intention TI & Planning T2 & Self-efficacy $T 2$ & F\&V TI & F\&V T2 \\
\hline Range & & & $1-4$ & $1-4$ & $1-4$ & Open & Open \\
$M$ & 37.46 & 1.82 & 2.77 & 2.17 & 2.86 & 3.10 & 3.54 \\
$S D$ & 10.72 & .36 & 0.90 & 0.96 & 0.93 & 1.45 & \\
Intention & .02 & $.27^{* *}$ & 1.00 & & & \\
Planning & $.09^{* *}$ & $.19^{* *}$ & $.38^{* *}$ & 1.00 & & \\
Self-efficacy & $-.13^{* *}$ & $.18^{* *}$ & $.36^{* *}$ & $.63^{* *}$ & .00 & $.54^{* *}$ & 1.00 \\
Diet T1 & $-.11^{* *}$ & $.21^{* *}$ & $.33^{* *}$ & $.39^{* *}$ & $.62^{* *}$ & $.70^{* *}$ \\
Diet T2 & -.02 & $.19^{* *}$ & $.31^{* *}$ & $.53^{* *}$ & 1.00 \\
\hline
\end{tabular}

Sex: $1=$ male, $2=$ female; $\mathrm{T} 1=$ Time $1, \mathrm{~T} 2=$ Time $2 . \mathrm{F} \& \mathrm{~V}=$ portions of fruit and vegetables per day (free format, openended). ${ }^{*} p<.05 ;{ }^{*} p<.01$. 


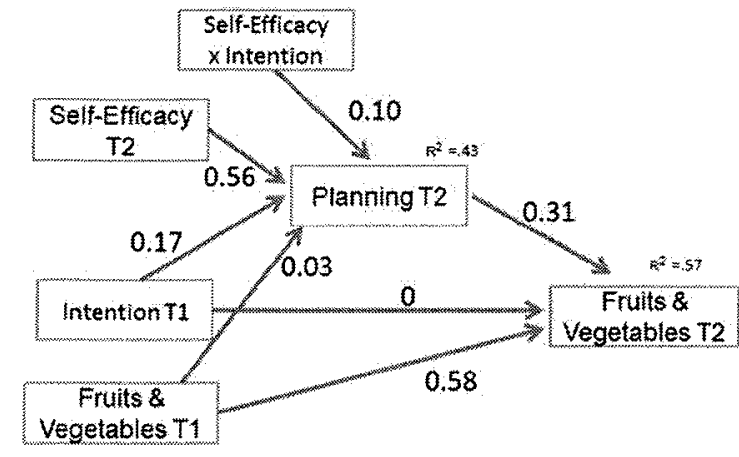

Figure 2. Moderated mediation model for 1140 German adults (Study 2). All coefficients $p<.01$ (except for the intentionbehavior relation).

Dietary behavior was assessed at both points in time. After providing the definition of "one serving," fruit and vegetable intake was measured using an open-ended item: "How many servings of fruit and vegetables did you eat on an average day?" Fruit and vegetable intake at Time 1 averaged 3.10 servings per day, $S D=1.45$, which is below the WHO recommendations for fruit and vegetable intake (5-a-Day; WHO, 2003).

\section{Results}

Moderated mediation analyses were run to replicate the findings of Study 1. Model 3, again, did not yield a significant moderation effect, which means that the Self-Efficacy $\times$ Planning interaction did not reach significance. But it did in Model 2, indicating that the moderation effect exists at the left side of the mediating mechanism (see Figure 2). First, self-efficacy $(B=0.56$, $p<.01)$ emerged as the best predictor of planning, followed by intention $(B=0.17, p<.01)$, and the interaction between intentions and self-efficacy $(B=0.10, \quad p<.01)$. Together, these variables accounted for $43 \%$ of the planning variance.

Second, baseline dietary behavior was the best predictor of T2 diet $(B=0.58, p<.01)$, followed by planning $(B=0.31, p<.01)$, overall accounting for $57 \%$ of the behavior variance, whereas intentions did not make a contribution. Thus, there is a full mediation of the intention-behavior relation via planning, moderated by self-efficacy.

This analysis corroborated the hypothesized mediation effect, which is conditional on the value of self-efficacy, and thus underscores the finding that planning translates intentions into behavior. This mediation did not materialize within the subgroup of individuals with low levels of self-efficacy. German participants

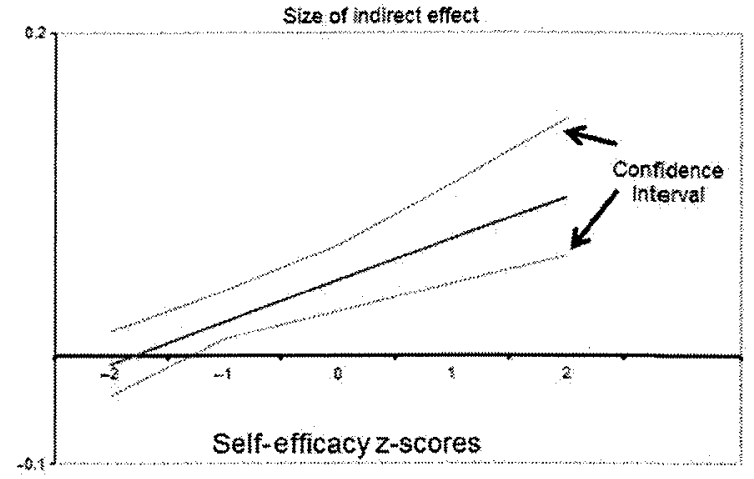

Figure 3. Regions of significance: The higher the moderator (self-efficacy $z$-scores), the larger the size of the mediation effect (Study 2).

needed a value above 1.83 on the $1-4$ scale to allow for a significant mediation effect. When splitting the sample at this point, the mediation for the high self-efficacy group was significant (Sobel $z=8.63, p<.0001$ ), whereas the mediation for the low self-efficacy group was not (Sobel $z=0.61$, $p=.54$ ). In other words, the size of the conditional indirect effect varied along levels of the moderator. At the highest level of self-efficacy, the indirect effect was $.61, p<.01$. At its mean level, the indirect effect was .32, $p<.01$, and at its lowest level there was no mediation at all. Figure 3 demonstrates the continuous relationship between the moderator (self-efficacy) and the size of indirect effect based on standard scores.

\section{GENERAL DISCUSSION}

The present study has confirmed the common assumption that planning can operate as a mediator of the intention-behavior relationship. The main contribution, however, lies in the extension of the mediator model into a moderated mediation model and its replication with baseline behavior as a covariate. It was hypothesized that perceived self-efficacy may be a necessary precondition for the mediation process. Self-efficacious persons hold optimistic beliefs about their capability to control their dietary behaviors, which might help them to generate plans or to enact their planning. Therefore, self-efficacious people might be more likely to translate their intentions into action. In other words, planning does not translate intentions into behavior if a person has severe selfdoubts. The present findings in two samples corroborate previous studies on physical activity (Lippke et al., 2009) and nutrition behaviors (Gutiérrez-Doña et al., 2009). 
This leads to the importance of the two present studies. First, moderated mediation elucidates the mechanisms of dietary change. Mediation obviously does not apply to everyone in the same way. There are subgroups of people for whom a putative causal mechanism does not hold true. In the present case, this is the subgroup of poorly selfefficacious individuals. However, other research has found other relevant moderators, such as sex (Renner et al., 2008), age (Renner et al., 2007), subjective residual life-expectancy (Ziegelmann, Lippke, \& Schwarzer, 2006), or intention (Wiedemann et al., 2009).

Second, the question arises as to how the present research can facilitate the design of interventions. It is obvious that individuals with very low selfefficacy are at a disadvantage in terms of the adoption of healthy dietary behaviors. People who report low perceived self-efficacy may not benefit from planning interventions. It does not make much sense to merely teach people how to plan their behavior better or how to improve their intention levels. They first need to gain more confidence in their own resources to change or maintain a healthy diet even when barriers prevail. This might be promoted in explicit selfefficacy interventions before offering the usual planning treatments (Luszczynska, Tryburcy, \& Schwarzer, 2007).

Some limitations are to be mentioned. The first study was only cross-sectional. The replication of its results by the second study, however, adds value. Together with the previous ones (GutiérrezDoña et al., 2009; Lippke et al., 2009), there are now five independent analyses in four countries that have accumulated evidence for self-efficacy as a moderator of the intention-planning-behavior relationship.

Enrichment of self-reported behavior by more refined or objective measures is desirable. There is no easy way to examine directly the validity of such self-reports. However, in general, self-reports of dietary behavior have been found sufficiently valid (Armitage \& Conner, 2001).

Moreover, these studies are not experimental ones and do not allow for causal inferences. Experimental causal chain designs would be an alternative option to examine the intention-behavior mediation by planning (Reuter, Ziegelmann, Wiedemann, \& Lippke, 2008).

Nevertheless, the present two studies from Thailand and Germany are innovative because they extend the common mediator models by a moderating factor. This can guide future research aimed at varying the kinds and number of such moderators to accumulate further evidence on the mechanisms of dietary change. Research also needs to compare various moderated mediation models to extend our understanding of health behavior change in different contexts, for different behaviors, and for different subgroups of individuals.

\section{REFERENCES}

Abraham, C., \& Sheeran, P. (2000). Understanding and changing health behaviour: From health beliefs to self-regulation. In P. Norman, C. Abraham, \& M. Conner (Eds.), Understanding and changing health behaviour (pp. 3-24). Amsterdam: Harwood.

Aiken, L. S., \& West, S. G. (1991). Multiple regression: Testing and interpreting interactions. Thousand Oaks, CA: Sage.

Armitage, C. J., \& Conner, M. (2001). Efficacy of the theory of planned behaviour: A meta-analytic review. British Journal of Social Psychology, 40, 471-499.

Bandura, A. (1997). Self-efficacy: The exercise of control. New York: Freeman.

Chapman, J., Armitage, C. J., \& Norman, P. (2009). Comparing implementation intention interventions in relation to young adults' intake of fruit and vegetables. Psychology \& Health, 24, 317-332.

Enders, C. K. (2001). A primer on maximum likelihood algorithms available for use with missing data. Structural Equation Modeling, 8, 128-141.

Godin, G., \& Kok, G. (1996). The theory of planned behavior: A review of its applications to healthrelated behaviors. American Journal of Health Promotion, 11, 87-97.

Gollwitzer, P. M., \& Sheeran, P. (2006). Implementation intentions and goal achievement: A meta-analysis of effects and processes. Advances in Experimental Social Psychology, 38, 69-119.

Gutiérrez-Doña, B., Lippke, S., Renner, B., Kwon, S., \& Schwarzer, R. (2009). How self-efficacy and planning predict dietary behaviors in Costa Rican and South Korean women: A moderated mediation analysis. Applied Psychology: Health \& Well-Being, 1, 91-104.

Kenny, D. A. (2008). Reflections on mediation. Organizational Research Methods, 11, 353-358.

Linde, J. A., Rothman, A. J., Baldwin, A. S., \& Jeffery, R. W. (2006). The impact of self-efficacy on behavior change and weight change among overweight participants in a weight loss trial. Health Psychology, 25, 282-291.

Lippke, S., Wiedemann, A. U., Ziegelmann, J. P., Reuter, T., \& Schwarzer, R. (2009). Self-efficacy moderates the mediation of intentions into behavior via plans. American Journal of Health Behavior, 33, 521-529.

Luszczynska, A., Sobczyk, A., \& Abraham, C. (2007). Planning to reduce weight: Implementation intentions intervention helps to reduce body weight among overweight or obese women by prompting action planning. Health Psychology, 26, 507-512.

Luszczynska, A., Tryburcy, M., \& Schwarzer, R. (2007). Improving fruit and vegetable consumption: A selfefficacy intervention compared to a combined 
self-efficacy and planning intervention. Health Education Research, 22, 630-638.

MacKinnon, D. (2008). Statistical mediation analysis. Mahwah, NJ: Lawrence Erlbaum Associates.

Norman, P., \& Conner, M. (2005). The theory of planned behavior and exercise: Evidence for the mediating and moderating roles of planning on intention-behavior relationships. Journal of Sport \& Exercise Psychology, 27, 488-504.

Preacher, K. J., Rucker, D. D., \& Hayes, A. F. (2007). Addressing moderated mediation hypotheses: Theory, methods, and prescriptions. Multivariate Behavioral Research, 42, 185-227.

Renner, B., Kwon, S., Yang, B.-H., Paik, K.-C., Kim, S. H., Roh, S., et al. (2008). Social-cognitive predictors of dietary behaviors in South Korean men and women. International Journal of Behavioral Medicine, 15, 4-13.

Renner, B., Spivak, Y., Kwon, S., \& Schwarzer, R. (2007). Does age make a difference? Predicting physical activity of South Koreans. Psychology and Aging, 22, 482-493.

Reuter, T., Ziegelmann, J. P., Wiedemann, A. U., \& Lippke, S. (2008). Dietary planning as a mediator of the intention-behavior relation: An experimentalcausal-chain design. Applied Psychology, 57, 194-207.

Scholz, U., Nagy, G., Göhner, W., Luszczynska, A., \& Kliegel, M. (2009). Changes in self-regulatory cognitions as predictors of changes in smoking and nutrition behaviour. Psychology \& Health, 24, 545-561.

Scholz, U., Sniehotta, F. F., Burkert, S., \& Schwarzer, R. (2007). Increasing physical exercise levels: Agespecific benefits of planning. Journal of Aging and Health, 19, 851-866.

Schwarzer, R. (2008). Modeling health behavior change: How to predict and modify the adoption and maintenance of health behaviors. Applied Psychology, 57, 1-29.

Schwarzer, R., \& Jerusalem, M. (1995). Generalized Self-Efficacy Scale. In J. Weinman, S. Wright, \& M. Johnston (Eds.), Measures in health psychology: A user's portfolio. Causal and control beliefs (pp. 35-37). Windsor, UK: NFER-Nelson.

Schwarzer, R., Luszczynska, A., Ziegelmann, J. P., Scholz, U., \& Lippke, S. (2008). Social-cognitive predictors of physical exercise adherence: Three longitudinal studies in rehabilitation. Health Psychology, 27, 854-863.

Shaikh, A. R., Yaroch, A. L., Nebeling, L., Yeh, M. C., \& Resnicow, K. (2008). Psychosocial predictors of fruit and vegetable consumption in adults: A review of literature. American Journal of Preventive Medicine, 34, 535-543.

Sniehotta, F. F. (2009). Towards a theory of intentional behaviour change: Plans, planning and self-regulation. British Journal of Health Psychology, 14, 261-273.

Steptoe, A., Perkins-Porras, L., McKay, C., Rink, E., Hilton, S., \& Cappuccio, F. P. (2003). Psychological factors associated with fruit and vegetable intake and with biomarkers in adults from a low-income neighborhood. Health Psychology, 22, 148-155.

WHO (2003). Fruit, vegetables and NCD disease prevention. Geneva, Switzerland: WHO.

Wiedemann, A. U., Schüz, B., Sniehotta, F. F., Scholz, U., \& Schwarzer, R. (2009). Disentangling the relation between intentions, planning, and behaviour: A moderated mediation analysis. Psychology \& Health, 24, 67-79.

Ziegelmann, J. P., Lippke, S., \& Schwarzer, R. (2006). Subjective residual life expectancy in health self-regulation. Journals of Gerontology: Psychological Sciences, 61B, 195-201. 